OPEN ACCESS

Edited by:

Dominik Wolf,

Innsbruck Medical University, Austria

Reviewed by:

Bruno Quesnel,

Centre Hospitalier Regional et

Universitaire de Lille, France

Ying-Jun Chang,

Peking University People's Hospital,

China

*Correspondence:

Alexandar Tzankov

alexandar.tzankov@usb.ch

Specialty section:

This article was submitted to

Cancer Immunity

and Immunotherapy,

a section of the journal

Frontiers in Immunology

Received: 08 November 2021

Accepted: 03 February 2022

Published: 22 February 2022

Citation:

Menter T and Tzankov A (2022) Tumor Microenvironment in Acute Myeloid Leukemia: Adjusting Niches.

Front. Immunol. 13:811144. doi: 10.3389/fimmu.2022.811144

\section{Tumor Microenvironment in Acute Myeloid Leukemia: Adjusting Niches}

\author{
Thomas Menter and Alexandar Tzankov* \\ Pathology, Institute of Medical Genetics and Pathology, University Hospital Basel, University of Basel, Basel, Switzerland
}

Acute myeloid leukemias (AML) comprise a wide array of different entities, which have in common a rapid expansion of myeloid blast cells leading to displacement of normal hematopoietic cells and also disruption of the microenvironment in the bone marrow niches. Based on an insight into the complex cellular interactions in the bone marrow niches in non-neoplastic conditions in general, this review delineates the complex relationship between leukemic cells and reactive cells of the tumor microenvironment (TME) in AML. A special focus is directed on niche cells and various T-cell subsets as these also provide a potential therapeutic rationale considering e.g. immunomodulation. The TME of AML on the one hand plays a vital role for sustaining and promoting leukemogenesis but - on the other hand - it also has adverse effects on abnormal blasts developing into overt leukemia hindering their proliferation and potentially removing such cells. Thus, leukemic cells need to and develop strategies in order to manipulate the TME. Interference with those strategies might be of particular therapeutic potential since mechanisms of resistance related to tumor cell plasticity do not apply to it.

Keywords: AML, TME, bone marrow niches, bone marrow stromal cells, T-cells

\section{INTRODUCTION}

Acute myeloid leukemia (AML) can be defined as a clonal expansion of hematopoietic progenitor cells showing a stop of differentiation and maturation at various stages (1). AML has a severe impact on affected patients with a general five-year survival rate of $24 \%$, a median survival of 8.5 months, and an even worse prognosis in the most commonly affected patient group of people over the age of 65 showing a median survival of only 2.7 months (2). This data and the fact that no increase in survival rates could be achieved in the last decades, show the urgent need for improved treatment modalities.

The mainstay of AML therapy includes intensive chemotherapy and allogeneic hematopoietic cell transplantation (AHCT) (3). The rationale behind AHCT is the idea that blasts remaining after chemotherapy will be eliminated by the transplanted donor-immune cells (graft-versus-leukemia effect). However, in a considerable fraction of patients, relapses occur. On the other hand, many especially elderly - AML patients are not eligible for this therapeutic option (4) and, thus, other therapeutic strategies must be explored. Improved understanding of the biology of AML and especially its microenvironment, including the exploration of the applicability of chimeric antigenreceptor $\mathrm{T}$ cells (CAR-T), might open new treatment options and significantly improve the outcome of patients. A key to achieve this goal is a profound understanding of the bone marrow niche, which provides physical protection and release of pro-survival factors for leukemia cells $(5,6)$, and the 
interaction between AML blasts and the immune system as potential target for immunotherapeutic approaches $(7,8)$.

As hematopathologists, we are confronted daily with evaluation of bone marrow biopsies and the characterization of its cellular components. This work has resulted in the conceptualization of various own studies dealing with the TME of hematopoietic neoplasms, which will be presented in this review along with seminal publications of other groups. So the focus of this review is the TME of myeloid tumors, particularly AML, from the viewpoint of histopathology that may mechanistically explain how AML blasts interact with the TME to support growth and survival. For a detailed view on therapeutic approaches targeting the TME in AML, we refer to other excellent reviews focusing on that topic $(9,10)$.

\section{THE MICROENVIRONMENT OF THE BONE MARROW NICHE}

The term "bone marrow niche(s)" has been coined to describe the specialized interplay of various cells and soluble factors providing the basis for sufficient and well-regulated hematopoiesis from the hematopoietic stem cells (HSC).

The bone marrow consists of a delicate vascular architecture of arterioles, veins and specialized sinusoids that enable trafficking of cells and soluble factors to the blood stream and vice versa, particularly through the fenestrated basal lamina of the sinusoids (11). Another important component of the bone marrow niches are stromal cells, which to a large extent comprise the adipose tissue, a longtime neglected component (12). Many authors distinguish a perivascular and an endosteal niche (10). It is still a matter of debate whether this distinction really can be made, since there is cumulating evidence in the support of the existence only of the former (13).

Hematopoiesis occurs in a circadian fashion effectuated by sympathetic nerve fibers in the bone marrow (14), and HSC themselves have been shown to be subject to respective oscillation, which is orchestrated by the sympathetic nervous system (15). Signaling via $\beta 3$-adrenergic receptors regulates nestin-expressing mesenchymal cells and their cell progenitors (MSC) (16), which are of core importance for the perivascular bone marrow niches (17). As a net effect, $\beta 3$-adrenergic signaling e.g. regulates trafficking of HSC (18).

The endosteal bone marrow niche (17) has been described as a shelter for HSC, and its regulation is orchestrated by osteoblasts and their progenitors (19). Osteoblasts form protective layers for HSC, they can also keep them in a non-circulatory state via cellcell adhesion molecules (20). This niche is preserved after treatment by chemotherapy and radiation, being the source of bone marrow renewal after such insults (21). As also capillaries seem to play an as important role in the endosteal niche as in the perivascular niche, it has been proposed to relinquish the separation between different niches. Just recently Panvini et al. presented human data on the presence of nestin+ capillary-like tubes (NCLTs), not surrounded by sub-endothelial perivascular cells in direct contact to the bone line and spatially correlated with hematopoietic stem/progenitor cells and possibly involved in regulating human hematopoiesis within the endosteal compartment (22). This group also showed that the endosteal niche capillary network gets destroyed in the course of AML evolvement in favor of the central perivascular niche.

The perivascular niche is considerably (about 9 times) larger. Its MSC can differentiate into osteoblasts, adipocytes, chondrocytes and fibroblasts (23), and are particularly important for HSC by secreting factors such as C-X-C motif chemokine 12 (CXCL12), stem cell factor (SCF) and interleukin (IL) 7 (16). Vice versa, MSC can be modulated by HSC to improve their own microenvironment (24). The most voluminous compound of the perivascular niche, the adipocytes of the bone marrow, have been shown to be different from adipocytes elsewhere in the body. Their amount steadily increases during lifetime and they are involved in HSC maintenance and proliferation by secreting adipokine and adiponectin (25), in addition of being an important source of nutrients for bone marrow cells. Production of CXCL12, IL3 and IL6 has also been documented for this cell type (26). Finally, the vascular partition consists of sinusoids and arterioles, which - based on single cell analysis must be regarded as different subcompartments $(27,28)$, e.g. sinusoids being mainly involved in cell egression from the bone marrow, while arterioles play a central role in nutrient and oxygen supply.

Macrophages - as in many other forms of TME - also are a pivotal part of the bone marrow niches. They can give rise to osteoclasts, influence osteoblasts and CXCL12-secretion by MSC to maintain homeostasis of HSC (29). Interestingly, the progenies of HSC, megakaryocytes also play a backloop role for HSC by secreting several cytokines such as insulin-like growth factor 1, platelet factor 4 and transforming growth factor beta (TGF $\beta)$ (30).

\section{THE TUMOR MICROENVIRONMENT OF MDN AND MPN: SIMILARITIES AND DIFFERENCES TO AML}

A weighty proportion of AML cases does not present as de novo disease but represents clinical or at least genetically perceptible evolution (31) of background clonal hematopoietic stem cell disorders such as myelodysplastic syndromes (MDS) that are now proposed to be called myelodysplastic neoplasms (MDN), or myeloproliferative neoplasms (MPN), the microenvironment of which has been the focus of research. MDN patients carry a high risk (up to 25\%) of developing AML (32), while in MPN this risk is more variable, depending on the respective entity, and is below $10 \%$. Interestingly in this regard, MDN cells can induce transformation of normal MSC into MSC with proinflammatory characteristics, which can then support leukemic progression (33), while vanishing nestin-positive niches is a well-established mechanism of MPN pathogenesis (34). Moreover, it has been shown in animal models that certain molecular dysfunctions in MSC can induce an MPN-like phenotype $(35,36)$. This just shows two brief insights into the interaction and relationship of 
neoplastic ells and their environment of these disease groups. In the following paragraphs when focusing on different cell subsets and soluble factors, we will figure out current knowledge in regard to the TME of AML.

\section{THE ROLE OF MESENCHYMAL STEM CELLS AND THEIR PROGENIES IN AML}

MSC are pluripotent cells that can differentiate into different types of mature cells as described above. During lifetime, there is a "physiological" change of MSC, which is reflected by increase of adipocytes and loss of osteoblasts (37). This alteration might also explain the well-known increasingly reduced bone marrow cellularity in the course of life. The underlying change of MSC differentiation is achieved via different mechanisms, including altered cytokine levels, resulting in decreased Wnt-related signaling and intensified RhoA-related signaling (38) as well as reduced Runx2 signaling, which is important for osteoblastic differentiation (39). "Senescence" that can be attributed to (cumulative effects of) pro-inflammatory cytokines, and changes of the sympathetic nerve system during life affect MSC (40). Indeed and as a cumulative result of altered signaling in cancer, nestin-positive MCS are significantly reduced in several hematologic malignancies. In a study on the TME of MPN, we could demonstrate that there is both a reduction of sympathetic nerve fibers and, consecutive, of nestin-expressing MSC in MPN, which is linked to the effects of proinflammatory cytokines that are increased in $\mathrm{MPN}$, and can be to a part reverted by administering $\beta 3$-adrenergic agonists (34). Interestingly, reduced numbers of nestin-positive MSC also correlate with another inflammatory condition, GvHD in AHCT patients (41). On the other hand, the role of nestin-positive MSC is different in AML as here, no depletion of these MSC has been observed (Figures 1A, B) and it is speculated that AML blasts are in need of MSC for survival and chemotherapy resistance, being dependent on the oxidative phosphorylation and tricarboxylic acid cycle activity, and antioxidant defense of the latter (42).
Whether the genuine disruption of MSC niches in MPN (34) compared to rather increased MSC-niche densities MDN (43) may additionally explain the higher transformation rate into $\mathrm{AML}$ of the latter, is an intriguing hypothesis that remains to be resolved.

Analogously to what has been mentioned in the previous section discussing the relationship between MPN and their TME, mutations can also occur in the MSC themselves, which is documented in MPN linked to mutations in Ptpn11 (44) or progression of AML fostered by Ctnnb1 mutations in osteoblasts (45) in mouse models. This shows a new path of leukemogenesis, initiated not by mutations occurring in HSC but in MSC with secondary mutations occurring in the blasts. Similar to what is known from studies on bone marrow senescence, disruption of sympathetic nerve signaling also happens in AML. In mouse models on both AML and MPN, the destruction of Schwann cells and reduced sympathicotonus significantly altered bone marrow niches and promoted the increase of leukemic stem cells and disease progression $(34,46)$. Interestingly, $\beta 3$-adrenergic agonists helped to restore physiological conditions and prevented disease progression.

AML blasts can push MSC to differentiate into osteoblasts, being as supportive for leukemia as for HSC in general (47), and via the mechanism of leukemic stem cell protection - in the endosteal niche in particular (48). This seems to occur via secretion of proinflammatory cytokines such as CCL3 or thrombopoietin (TPO). Single cell RNA sequencing studies could already provide deeper insights into the reprogramming of MSC in vivo: Baryawno et al. elegantly demonstrated that different MSC are involved, including e.g. significant changes in osteoblast subsets and decreases differentiation into adipocytes, accompanied by upregulation of hypoxia-related genes in MSC (28).

Adipocytes are getting diminished by AML expansion in the bone marrow, which seems to be not only due to spatial disproportion, but also by preferential MSC-differentiation towards the osteoblastic lineage (49). On the other hand, adipocytes provide nurture to AML cells via release of fatty
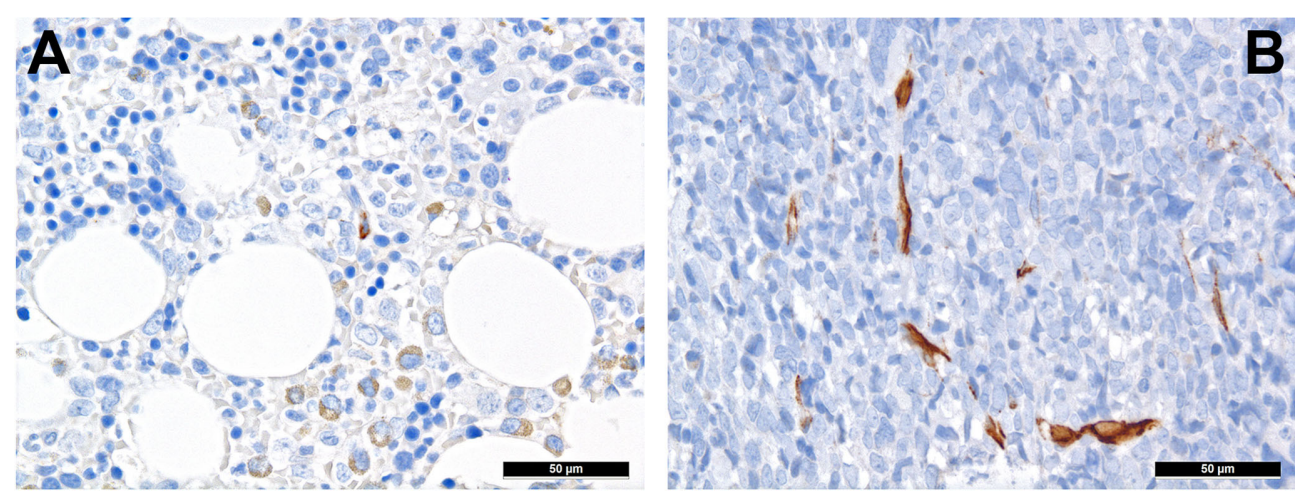

FIGURE 1 | Distribution of nestin+ cells of the perivascular niches in AML. (A) Nestin expression in MSC-equivalents in normal bone marrow (immunohistochemistry, 400x); (B) Increased presence of nestin-positive MSC-equivalents in a case of AML suggesting importance of the former cells for AML survival (immunohistochemistry, 400x). 
acids and also are important for bioavailability/unavailability of many lipophilic drugs (50), so their importance for AML cells is still difficult to interpret. Interestingly, the latter property of these cells is suspected being one reason for the inferior survival of elderly AML-patients as adipocyte-rich niches may provide a protective environment for AML blasts (51).

AML blast tightly interact with the endothelium. It has long been known that AML show an increased microvascular density compared to non-neoplastic bone marrow (52). Vascular endothelial growth factor (VEGF) is a major player in this relationship: besides fostering angiogenesis it can also inhibit apoptotic signaling in AML cells and support proliferation by upregulating secretion of GM-CSF by endothelial cells (53). Moreover, adhesion of leukemic stem cells through E-selectin to the vascular niche protects the former from the lethal effect of chemotherapy, which can be specifically counteracted (54).

Extracellular matrix components are an important factor for cell (im-)mobility and, thus, also a vital component of the TME. Already ten years ago, we could show the importance of RHAMM/CD168 (Figure 2A), the receptor for hyaluronic acid-mediated motility, as a negative prognostic marker for AML patients (55). CD44 that also interacts with hyaluronic acid (Figure 2B), is a type I transmembrane protein serving - especially in its sialofucosylated form - as adhesion molecule with ligands such as osteopontin, E- and L-selectin and fibronectin, and is an important factor for homing of HSC, and particularly of leukemic stem cells (56). Blocking CD44, the most commonly variant of which expressed in AML is v6 that is moreover linked to poor outcome, has been shown to prevent persistence of AML blasts in the bone marrow niche upon chemotherapy, which is otherwise linked to the quiescentpromoting- and, thus, cell-protective TME functions of CD44 (57).

\section{THE ROLE OF LYMPHOCYTES AND MONOCYTES IN AML IMMUNE ESCAPE}

As seen in many other tumors, immune escape is an important survival strategy for AML. AML blasts have been shown to impede the formation of immune synapses (58) and impair cytotoxic activity of T-cells (59). Generally, and in AML in particular, immune escape can be divided into different strategies including hiding of the malignant cells from the immune system up to manipulation of various immunecell subsets.

$\mathrm{T}$-cells can be divided into regulatory and cytotoxic $\mathrm{T}$-cell subgroups. Regulatory T-cells (Tregs) dampen inflammatory responses, both by secreting anti-inflammatory cytokines as well as silencing cytotoxic T-cells (60). Thus, Tregs' effects to provide protection from the immune system may be important for AML. AML blasts express one of the most potent cell-contact immune silencers, programmed death ligand 1 (PD-L1; Figures 3A, B), which increases with disease progression (61). They can also produce reactive oxygen species (62) and indolamine-2, 3-dioxygenase (IDO), which both promote differentiation towards Tregs (63). Just recently, a study by Ragaini et al. demonstrated that an IDO1-related immune gene signature predicts overall survival in AML (64). Another target to induce T-cell anergy is T-cell immunoglobulin and mucin domain 3 (TIM3), which binds to and is activated by galectin-9, the latter being highly expressed on AML blasts, which leads to an activation of several downstream signaling pathways such as the MAPK/ERK, PI3K- and AKT (65). TIM3 can stimulate the production of IDO and thus foster immune evasion (66). Yet, regarding the role of TIM3-expression AML, there are still conflicting results (67-69). Secretion of inducible T-cell co-stimulator ligand (ICOSL) and IDO's product, $\mathrm{N}$-formylkynurenine, furthermore contribute to an immunosuppressive environment stimulating the expansion of Tregs, while limiting cytotoxic activity $(70,71)$. Low Treg levels have been generally associated with better outcomes in AML (72). However the very dynamic nature of these interaction can be appreciated from the following example: in a retrospective cohort we could show higher numbers of FoxP3+ Tregs (Figure 4A) in the early phases after induction therapy are associated with higher complete remission rates and better overall AML survival (73), contrasting their role when assessed
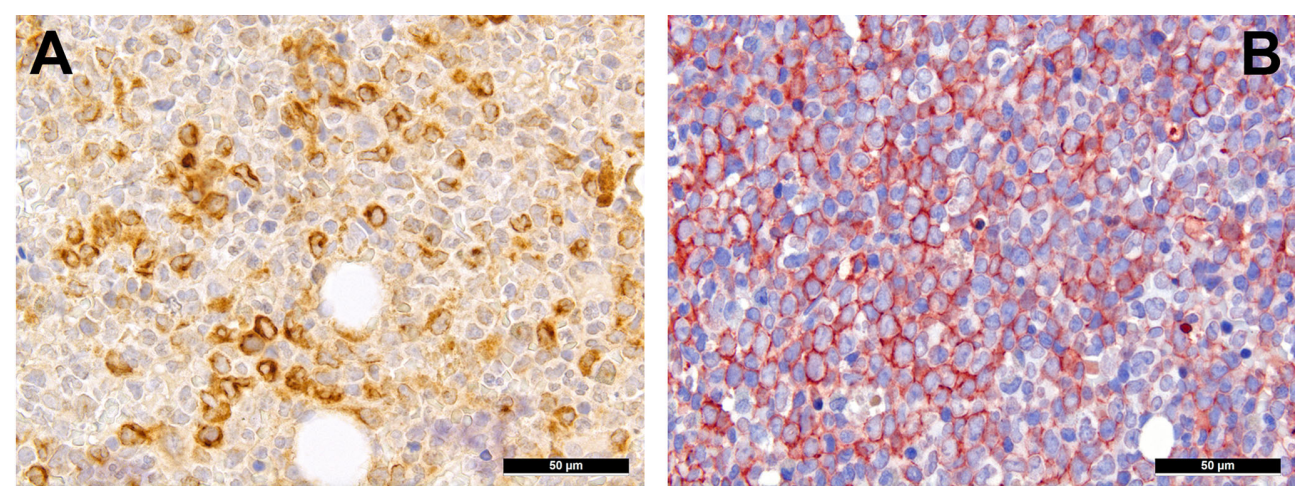

FIGURE 2 | Expression of hyaluronic acid binding proteins in AML. (A) Diffuse expression of RHAMM in AML cells (immunohistochemistry, 400x); (B) Diffuse expression of CD44v6 in AML cells (immunohistochemistry, 400x). 

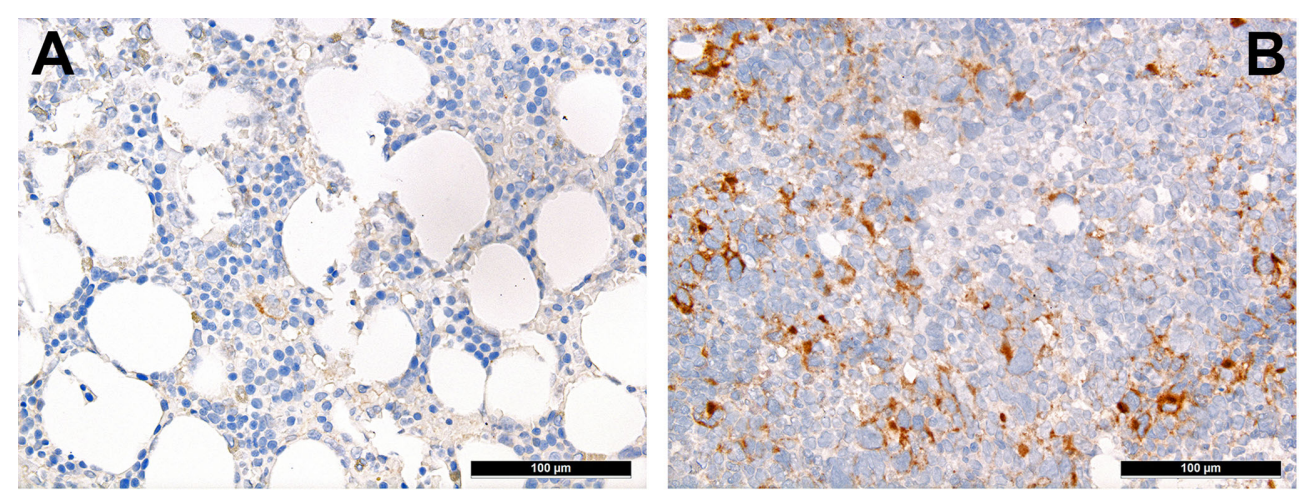

FIGURE 3 | Distribution of PD-L1+ mononuclear tumor-infiltrating cells in AML. Case of relapsing AML showing high expression of PD-L1 (B) in contrast to very scarce expression of PD-L1 in the adjacent non-neoplastic bone marrow (A; immunohistochemistry, 200x).

at baseline AML biopsies (74). We hypothesized that this is attributed to active changes of the T-cell compartment reflecting the stereotypic recovery of the immune system after chemotherapy. Due to their immunomodulatory abilities, the expanding Tregs could foster the recovery of normal hematopoietic cells effectuated e.g. by limiting activity of effector T-cells, which may otherwise react to potential neoepitopes unmasked due to cell destruction caused by chemotherapy. Accordingly, the beneficiary role of Tregs becomes evident when looking at lower rates of GvHD in Treg-high AHCT patients (75). Alongside, high expression levels of the surface molecules mentioned such as PD1/PD-L1 and TIM3 are associated with worse prognosis in AML, thus suggesting potential relevance for therapeutic interventions, with first immune checkpoint inhibition trials being underway (76) although - as alluded to above -investigations of the expression of these markers still produces conflicting results (69). Yet and in accordance with the described above, it seems that immune checkpoint inhibition as a single therapy is not successful, therefore currently combination therapies are being explored (77).
T-cell exhaustion can further be achieved by alterations of the metabolic microenvironment of AML, which can be characterized as glutamine-rich (78) and an arginine-deprived (79). Therefore, administering L-asparaginase (80) and inhibiting arginine deprival (81) have been both shown to be promising options for AML. Further immunomodulating drugs such as lenalidomide have also been tested in AML. In a translational side-project of a randomized clinical study (HOVON103 AML/SAKK 30/10), addressing the role of TME in AML treated by chemotherapy with or without addition of lenalidomide, we could show that its addition may be beneficial to (elderly) patients suffering from AML with multilineage dysplasia, where it led to a reduction of microvascularization and, likely, to an intensified specific $\mathrm{T}$ cell-driven anti-leukemic response (82). Lenalidomide promotes the degradation of two transcription factors, Aiolos and Ikaros, of the cereblonmediating signaling $(83,84)$. Lenalidomide affects both neoplastic cells - by facilitating apoptosis, and the surrounding T-cells - by activating them via enhanced secretion of IL 2 (85). Indeed, under lenalidomide, the amount of T-bet+ $\mathrm{T}$ cells more consistently increased (82), which might be interpreted as a sign
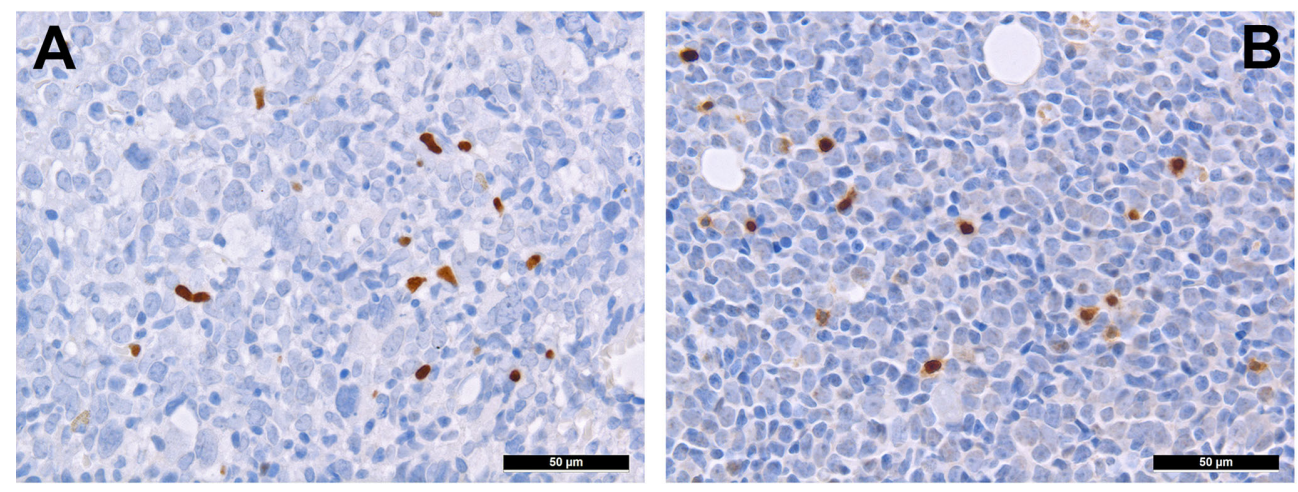

FIGURE 4 | Distribution of regulatory T-cells and TH1-cells in AML. Presence of regulatory T-cells expressing FOXP3 (A) and Tbet (B) in bone marrow involved by AML (immunohistochemistry, 400x). 
of increased $\mathrm{T}$ cell-driven immune response against the tumor cells. Consistently, this T-bet+ T-cell subgroup (Figure 4B) is a significant contributor to T-cell activation (86), and has a potential beneficiary effect on AML outcome as it fosters antiAML immunity (87).

The role of B-cells has not been investigated at a larger scale so far. Cheng et al. investigated the prognostic importance of the TME in AML and showed a negative impact of memory B-cells (yet not statistically significant) on survival, while increased numbers of naïve B-cells had a positive impact (88).

Besides T-cells of the adaptive immune system, AML blasts also alter the function of innate immune system cells, namely NK cells and macrophages. AML blasts downregulate surface molecules needed for their recognition by NK cells via the receptor natural killer group 2 member D (NKG2D), and release altered NKG2D-ligands reducing the cytotoxic activity of NK cells $(89,90)$. Another mechanism to evade NK-cell recognition and, thus, destruction is inhibiting release of interferon $\gamma$ (91). Similar to solid tumors, AML blasts induce a shift of macrophages towards M2 polarization, M2 macrophages being immunosuppressive, supporting angiogenesis and tissue repair (92). Elevated levels of M2 macrophages in AML patients have been described in vivo and in mouse models (93). Another population manipulated by AML blasts are myeloid-derived suppressor cells, which are derived from monocytes (94). These cells cause $\mathrm{T}$-cell inactivity via several mechanisms ranging from PD-L1 expression to secretion of cytokines such as IL10 and/or TGF $\beta$. In line with M2-macrophages and Tregs, these myeloid-derived suppressor cells are also more abundant in AML patients (94), and, consistently, they seem to be a risk factor for disease progression of MDN to overt AML (95). Finally, AML blasts also show a defective antigen-presentation by downregulation of human leukocyte antigens (HLAs) helping to render them invisible to immune cells (96).

These complex interactions between AML cells and nonneoplastic immunomodulating cells seems to represent a major source of difficulties for applying CAR-T in such instances (97), besides difficulties in identifying targets not also expressed by non-neoplastic HSC (98). As detailed above, induction of myeloid-derived suppressor cells and Tregs significantly reduces $\mathrm{T}$-cell responses, which also holds true for CAR-T responses. Targeting CD33, which is not only expressed on AML blasts, but also on the myeloid-derived suppressor cells is a potential strategy to overcome this dilemma (99). Respecting AML-TME interactions, a phase I/II trial is currently running to explore the application of CD44v6 CAR-T in AML (https:// clinicaltrials.gov/ct2/show/NCT04097301). Constructing CAR-T with costimulatory domains to dampen the influence of Tregs might be another potential approach (100). A further obstacle to the efficacy of CAR-T is the secretion of various soluble factors by AML blasts, which will be discussed in the next paragraph.

\section{SOLUBLE FACTORS AFFECTING THE TME}

AML cells depend on numerous cytokines and soluble factors provided by cells of the bone marrow niches. In addition, several adhesion factors seem to be essential for AML cells within these niches.

CXCL12 (Figure 5A) is secreted by MSC under the orchestration of sympathetic nervous signaling, and regulates leukocyte trafficking as mentioned above (101). Interactions with its receptor, CXCR4, increase retention of HSC to the bone marrow niches and decreases their progenies' migration into the bloodstream. Several years ago, we could show that active CXCR4 signaling is associated with an inferior prognosis in AML as a consequence of an increased retention to the bone marrow associated with an enhanced chemoresistance of leukemic cells (102). Indeed, under chemotherapy, AML cells often overexpress CXCR4 (Figure 5B) that facilitates overcoming apoptotic stimuli and improving cell survival by entering a state of quiescence and stromal protection, thus, being less amenable to the effects of cytotoxic drugs (103). CXCR4 antagonists such as plerixafor or the monoclonal antibody ulocuplumab are currently investigated in several
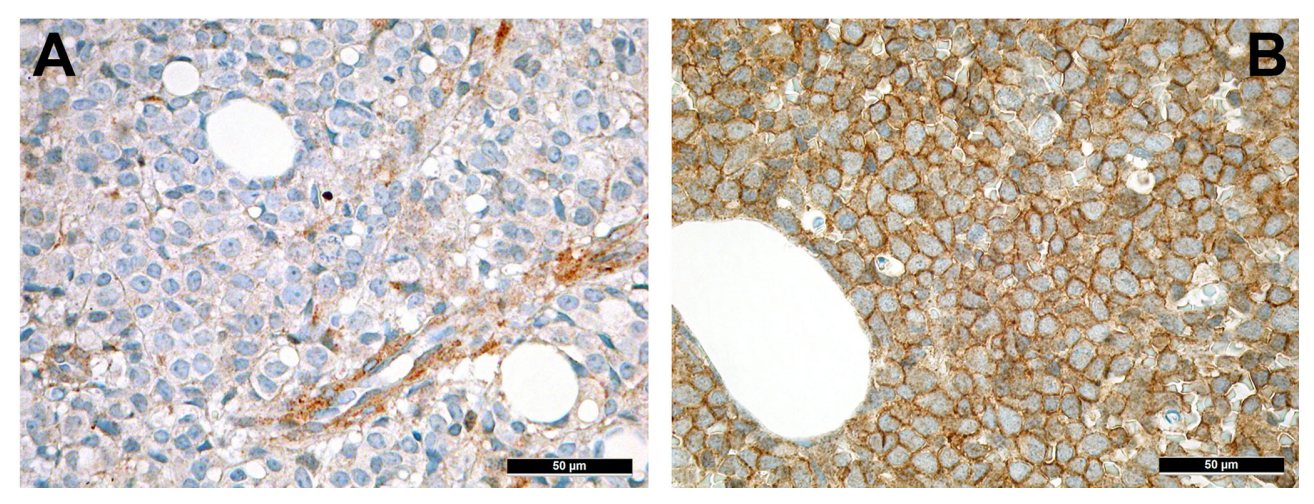

FIGURE 5 | Expression of members of the CXCL12-CXCR4 axis in AML. (A) Expression of CXCL12 in perivascular MSC-equivalents in AML (immunohistochemistry, 400x); (B) Diffuse expression of the receptor of CXCL12, CXCR4, on AML blasts (immunohistochemistry, 400x). 
clinical trials (104). CXCR4-antagonists mobilize leukemic stem cells into the blood stream and block several survival pathways as discussed above, thus rendering AML cells more chemosusceptible. Importantly, granulocyte colony-stimulating factor (G-CSF) that is commonly given to support recovery from chemotherapy, seems to antagonize CXCR4 effects too, and is claimed to improve AML outcomes by means of this mechanisms, too (105).

ILs are an integral component for the regulation of the immune system. AML blasts can secrete a variety of ILs to adjust the TME to their needs: secretion of IL1 $\beta$ promotes growth of blasts, thus, serving as an autocrine growth factor, while suppressing non-neoplastic HSC (106) also by overturning adrenergic signaling in the perivascular niches (see above). By binding circulating IL2 via CD25, AML blasts can reduce T-cell activity (107). IL8 seems to be important for chemoresistance (108), and its secretion by endothelial cells is propagated by AML blasts. IL10 is secreted by MSC of the TME and correlated with worse survival in AML (109). By secreting IL10, MSC can induce immune tolerance, a well-established function of IL10 (110), and thereby shield AML blasts from detection by the immune system.

\section{CONCLUSIONS}

In this review, we tried to give an overview of the massively expanding knowledge on the complex interactions of AML with their TME. The delicate structures and functions of the bone marrow niches are profoundly altered in order to help AML blasts to survive, expand and escape immune surveillance. Both, various cellular subsets as well as soluble factors play important roles in this settings (Figure 6). With more and more knowledge generated from treating solid tumors with immunotherapy, it is now also beginning to be explored in AML, especially in instances treated by chemotherapy. An area still not profoundly investigated is AML in the setting of AHCT. Indeed and as may be anticipated from the information on the interaction of AML with its TME reviewed here, increased knowledge on different pathways and

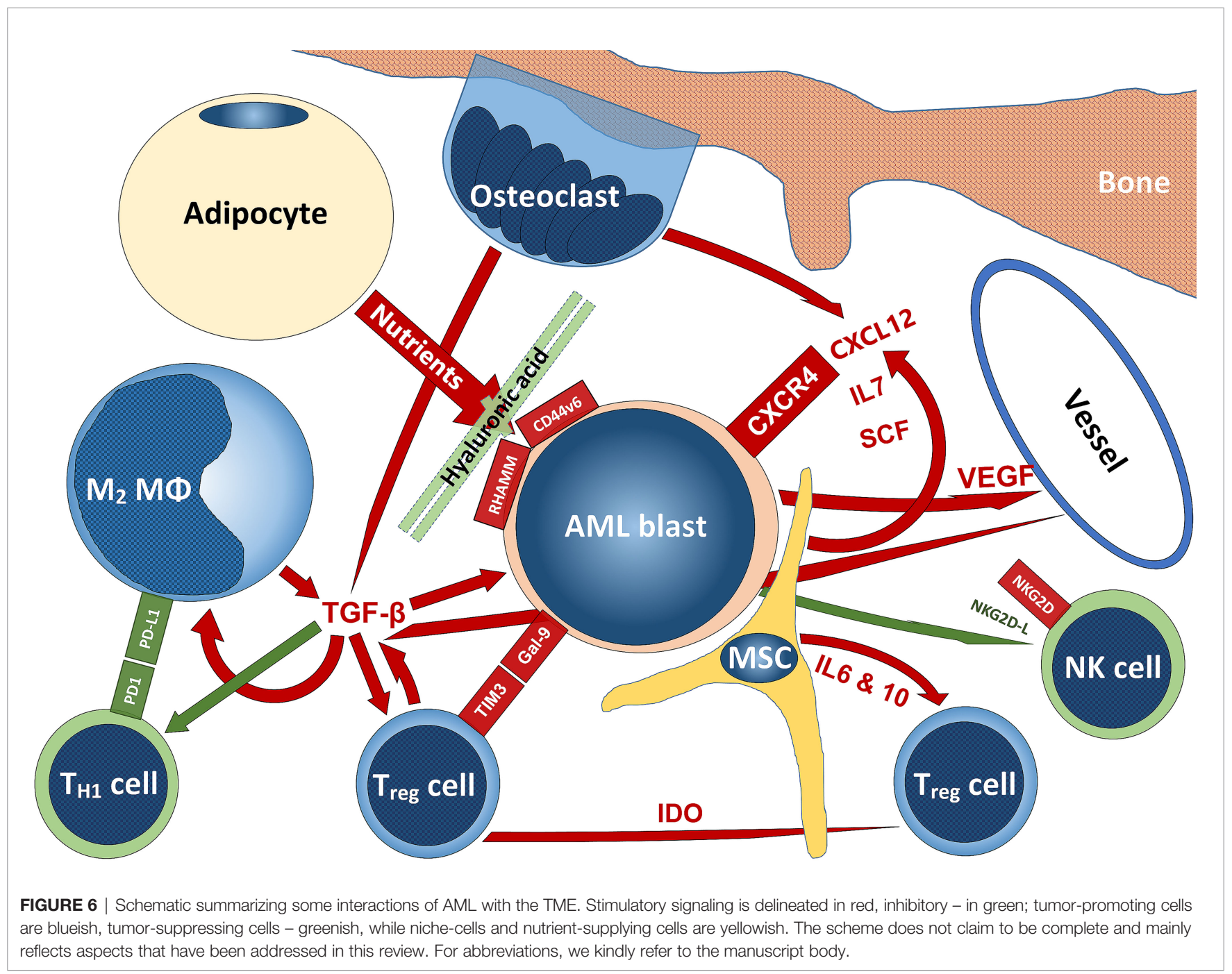


mechanisms of action mediated through the TMA that may - if therapeutically adjusted - counterbalance graft-versus-host-, while supporting graft-versus-leukemia effects in the setting of AML treated by AHCT has the potential to considerably improve outcome. Further understanding and finding modes of action of immunotherapies and therapies targeting non-immunologic AMLTME interactions to counterbalance the manipulative effects of AML blasts on the bone marrow niche and its constituents has the potential to improve the prognosis of AML patients both at initial

\section{REFERENCES}

1. Dohner H, Estey E, Grimwade D, Amadori S, Appelbaum FR, Buchner T, et al. Diagnosis and Management of AML in Adults: 2017 ELN Recommendations From an International Expert Panel. Blood (2017) 129 (4):424-47. doi: 10.1182/blood-2016-08-733196

2. Shallis RM, Wang R, Davidoff A, Ma X, Zeidan AM. Epidemiology of Acute Myeloid Leukemia: Recent Progress and Enduring Challenges. Blood Rev (2019) 36:70-87. doi: 10.1016/j.blre.2019.04.005

3. Gomez-Arteaga A, Gyurkocza B. Recent Advances in Allogeneic Hematopoietic Cell Transplantation for Acute Myeloid Leukemia. Curr Opin Hematol (2020) 27(2):115-21. doi: 10.1097/MOH.0000000000000572

4. Appelbaum FR. Impact of Allogeneic Hematopoietic Cell Transplantation on the Outcome of Older Patients With Acute Myeloid Leukemia. Best Pract Res Clin Haematol (2017) 30(4):320-6. doi: 10.1016/j.beha.2017.09.004

5. Mendez-Ferrer S, Bonnet D, Steensma DP, Hasserjian RP, Ghobrial IM, Gribben JG, et al. Bone Marrow Niches in Haematological Malignancies. Nat Rev Cancer (2020) 20(5):285-98. doi: 10.1038/s41568-020-0245-2

6. Witkowski MT, Kousteni S, Aifantis I. Mapping and Targeting of the Leukemic Microenvironment. J Exp Med (2020) 217(2). doi: 10.1084/ jem.20190589

7. Agrawal V, Gbolahan OB, Stahl M, Zeidan AM, Zaid MA, Farag SS, et al. Vaccine and Cell-Based Therapeutic Approaches in Acute Myeloid Leukemia. Curr Cancer Drug Targets (2020) 20(7):473-89. doi: 10.2174/ 1568009620666200502011059

8. Ustun C, Miller JS, Munn DH, Weisdorf DJ, Blazar BR. Regulatory T Cells in Acute Myelogenous Leukemia: Is it Time for Immunomodulation? Blood (2011) 118(19):5084-95. doi: 10.1182/blood-2011-07-365817

9. Sendker S, Reinhardt D, Niktoreh N. Redirecting the Immune Microenvironment in Acute Myeloid Leukemia. Cancers (Basel) (2021) 13 (6). doi: 10.3390/cancers13061423

10. Yao Y, Li F, Huang J, Jin J, Wang H. Leukemia Stem Cell-Bone Marrow Microenvironment Interplay in Acute Myeloid Leukemia Development. Exp Hematol Oncol (2021) 10(1):39. doi: 10.1186/s40164-021-00233-2

11. Birbrair A, Frenette PS. Niche Heterogeneity in the Bone Marrow. Ann N Y Acad Sci (2016) 1370(1):82-96. doi: 10.1111/nyas.13016

12. Bukowska J, Frazier T, Smith S, Brown T, Bender R, McCarthy M, et al. Bone Marrow Adipocyte Developmental Origin and Biology. Curr Osteoporos Rep (2018) 16(3):312-9. doi: 10.1007/s11914-018-0442-z

13. Beerman I, Luis TC, Singbrant S, Lo Celso C, Mendez-Ferrer S. The Evolving View of the Hematopoietic Stem Cell Niche. Exp Hematol (2017) 50:22-6. doi: 10.1016/j.exphem.2017.01.008

14. Katayama Y, Battista M, Kao WM, Hidalgo A, Peired AJ, Thomas SA, et al. Signals From the Sympathetic Nervous System Regulate Hematopoietic Stem Cell Egress From Bone Marrow. Cell (2006) 124(2):407-21. doi: $10.1016 /$ j.cell.2005.10.041

15. Hanoun M, Maryanovich M, Arnal-Estape A, Frenette PS. Neural Regulation of Hematopoiesis, Inflammation, and Cancer. Neuron (2015) 86(2):360-73. doi: 10.1016/j.neuron.2015.01.026

16. Mendez-Ferrer S, Michurina TV, Ferraro F, Mazloom AR, Macarthur BD, Lira SA, et al. Mesenchymal and Haematopoietic Stem Cells Form a Unique Bone Marrow Niche. Nature (2010) 466(7308):829-34. doi: 10.1038/nature09262

17. Nombela-Arrieta C, Pivarnik G, Winkel B, Canty KJ, Harley B, Mahoney JE, et al. Quantitative Imaging of Haematopoietic Stem and Progenitor Cell stages as well as in the relapse setting and achieving control in the minimal residual disease setting.

\section{AUTHOR CONTRIBUTIONS}

Both authors conceived and wrote the manuscript. All authors contributed to the article and approved the submitted version.

Localization and Hypoxic Status in the Bone Marrow Microenvironment. Nat Cell Biol (2013) 15(5):533-43. doi: 10.1038/ncb2730

18. Mendez-Ferrer S, Lucas D, Battista M, Frenette PS. Haematopoietic Stem Cell Release is Regulated by Circadian Oscillations. Nature (2008) 452 (7186):442-7. doi: 10.1038/nature06685

19. Calvi LM, Adams GB, Weibrecht KW, Weber JM, Olson DP, Knight MC, et al. Osteoblastic Cells Regulate the Haematopoietic Stem Cell Niche. Nature (2003) 425(6960):841-6. doi: 10.1038/nature02040

20. Loeffler D, Schroeder T. Symmetric and Asymmetric Activation of Hematopoietic Stem Cells. Curr Opin Hematol (2021) 28(4):262-8. doi: 10.1097/MOH.0000000000000644

21. Zhao M, Tao F, Venkatraman A, Li Z, Smith SE, Unruh J, et al. N-CadherinExpressing Bone and Marrow Stromal Progenitor Cells Maintain Reserve Hematopoietic Stem Cells. Cell Rep (2019) 26(3):652-69 e6. doi: 10.1016/ j.celrep.2018.12.093

22. Panvini FM, Pacini S, Montali M, Barachini S, Mazzoni S, Morganti R, et al. High NESTIN Expression Marks the Endosteal Capillary Network in Human Bone Marrow. Front Cell Dev Biol (2020) 8:596452. doi: 10.3389/ fcell.2020.596452

23. Bianco P, Robey PG. Skeletal Stem Cells. Development (2015) 142(6):1023-7. doi: 10.1242/dev.102210

24. Durand C, Charbord P, Jaffredo T. The Crosstalk Between Hematopoietic Stem Cells and Their Niches. Curr Opin Hematol (2018) 25(4):285-9. doi: 10.1097/MOH.0000000000000438

25. DiMascio L, Voermans C, Uqoezwa M, Duncan A, Lu D, Wu J, et al. Identification of Adiponectin as a Novel Hemopoietic Stem Cell Growth Factor. J Immunol (2007) 178(6):3511-20. doi: 10.4049/jimmunol. 178.6.3511

26. Kumar S, Geiger H. HSC Niche Biology and HSC Expansion Ex Vivo. Trends Mol Med (2017) 23(9):799-819. doi: 10.1016/j.molmed.2017.07.003

27. Sivaraj KK, Adams RH. Blood Vessel Formation and Function in Bone. Development (2016) 143(15):2706-15. doi: 10.1242/dev.136861

28. Baryawno N, Przybylski D, Kowalczyk MS, Kfoury Y, Severe N, Gustafsson $\mathrm{K}$, et al. A Cellular Taxonomy of the Bone Marrow Stroma in Homeostasis and Leukemia. Cell (2019) 177(7):1915-32.e16. doi: 10.1016/j.cell. 2019.04.040

29. Chow A, Lucas D, Hidalgo A, Mendez-Ferrer S, Hashimoto D, Scheiermann C, et al. Bone Marrow CD169+ Macrophages Promote the Retention of Hematopoietic Stem and Progenitor Cells in the Mesenchymal Stem Cell Niche. J Exp Med (2011) 208(2):261-71. doi: 10.1084/jem.20101688

30. Norozi F, Shahrabi S, Hajizamani S, Saki N. Regulatory Role of Megakaryocytes on Hematopoietic Stem Cells Quiescence by CXCL4/PF4 in Bone Marrow Niche. Leuk Res (2016) 48:107-12. doi: 10.1016/ j.leukres.2015.12.012

31. Lindsley RC, Mar BG, Mazzola E, Grauman PV, Shareef S, Allen SL, et al. Acute Myeloid Leukemia Ontogeny is Defined by Distinct Somatic Mutations. Blood (2015) 125(9):1367-76. doi: 10.1182/blood-2014-11-610543

32. Germing U, Kobbe G, Haas R, Gattermann N. Myelodysplastic Syndromes: Diagnosis, Prognosis, and Treatment. Dtsch Arztebl Int (2013) 110(46):78390. doi: 10.3238/arztebl.2013.0783

33. Medyouf H, Mossner M, Jann JC, Nolte F, Raffel S, Herrmann C, et al. Myelodysplastic Cells in Patients Reprogram Mesenchymal Stromal Cells to Establish a Transplantable Stem Cell Niche Disease Unit. Cell Stem Cell (2014) 14(6):824-37. doi: 10.1016/j.stem.2014.02.014 
34. Arranz L, Sanchez-Aguilera A, Martin-Perez D, Isern J, Langa X, Tzankov A, et al. Neuropathy of Haematopoietic Stem Cell Niche is Essential for Myeloproliferative Neoplasms. Nature (2014) 512(7512):78-81. doi: $10.1038 /$ nature13383

35. Wang L, Zhang H, Rodriguez S, Cao L, Parish J, Mumaw C, et al. NotchDependent Repression of miR-155 in the Bone Marrow Niche Regulates Hematopoiesis in an NF-kappaB-Dependent Manner. Cell Stem Cell (2014) 15(1):51-65. doi: 10.1016/j.stem.2014.04.021

36. Walkley CR, Shea JM, Sims NA, Purton LE, Orkin SH. Rb Regulates Interactions Between Hematopoietic Stem Cells and Their Bone Marrow Microenvironment. Cell (2007) 129(6):1081-95. doi: 10.1016/ j.cell.2007.03.055

37. Goltzman D. The Aging Skeleton. Adv Exp Med Biol (2019) 1164:153-60. doi: 10.1007/978-3-030-22254-3_12

38. Shi W, Xu C, Gong Y, Wang J, Ren Q, Yan Z, et al. RhoA/Rock Activation Represents a New Mechanism for Inactivating Wnt/beta-Catenin Signaling in the Aging-Associated Bone Loss. Cell Regener (2021) 10(1):8. doi: 10.1186/s13619-020-00071-3

39. Ji H, Cui X, Yang Y, Zhou X. CircRNA hsa_circ_0006215 Promotes Osteogenic Differentiation of BMSCs and Enhances OsteogenesisAngiogenesis Coupling by Competitively Binding to miR-942-5p and Regulating RUNX2 and VEGF. Aging (Albany NY) (2021) 13(7):10275-88. doi: 10.18632/aging.202791

40. Woods K, Guezguez B. Dynamic Changes of the Bone Marrow Niche: Mesenchymal Stromal Cells and Their Progeny During Aging and Leukemia. Front Cell Dev Biol (2021) 9:714716. doi: 10.3389/ fcell.2021.714716

41. Medinger M, Krenger W, Jakab A, Halter J, Buser A, Bucher C, et al. Numerical Impairment of Nestin(+) Bone Marrow Niches in Acute GvHD After Allogeneic Hematopoietic Stem Cell Transplantation for AML. Bone Marrow Transplant (2015) 50(11):1453-8. doi: 10.1038/bmt.2015.189

42. Forte D, Garcia-Fernandez M, Sanchez-Aguilera A, Stavropoulou V, Fielding C, Martin-Perez D, et al. Bone Marrow Mesenchymal Stem Cells Support Acute Myeloid Leukemia Bioenergetics and Enhance Antioxidant Defense and Escape From Chemotherapy. Cell Metab (2020) 32(5):829-43 e9. doi: 10.1016/j.cmet.2020.09.001

43. Flores-Figueroa E, Varma S, Montgomery K, Greenberg PL, Gratzinger D. Distinctive Contact Between CD34+ Hematopoietic Progenitors and CXCL12+ CD271+ Mesenchymal Stromal Cells in Benign and Myelodysplastic Bone Marrow. Lab Invest (2012) 92(9):1330-41. doi: 10.1038/labinvest.2012.93

44. Dong L, Yu WM, Zheng H, Loh ML, Bunting ST, Pauly M, et al. Leukaemogenic Effects of Ptpn11 Activating Mutations in the Stem Cell Microenvironment. Nature (2016) 539(7628):304-8. doi: 10.1038/ nature20131

45. Stoddart A, Wang J, Hu C, Fernald AA, Davis EM, Cheng JX, et al. Inhibition of WNT Signaling in the Bone Marrow Niche Prevents the Development of MDS in the Apc(del/+) MDS Mouse Model. Blood (2017) 129(22):2959-70. doi: 10.1182/blood-2016-08-736454

46. Hanoun M, Zhang D, Mizoguchi T, Pinho S, Pierce H, Kunisaki Y, et al. Acute Myelogenous Leukemia-Induced Sympathetic Neuropathy Promotes Malignancy in an Altered Hematopoietic Stem Cell Niche. Cell Stem Cell (2014) 15(3):365-75. doi: 10.1016/j.stem.2014.06.020

47. Battula VL, Le PM, Sun JC, Nguyen K, Yuan B, Zhou X, et al. AML-Induced Osteogenic Differentiation in Mesenchymal Stromal Cells Supports Leukemia Growth. JCI Insight (2017) 2(13). doi: 10.1172/jci.insight.90036

48. Ishikawa F, Yoshida S, Saito Y, Hijikata A, Kitamura H, Tanaka S, et al. Chemotherapy-Resistant Human AML Stem Cells Home to and Engraft Within the Bone-Marrow Endosteal Region. Nat Biotechnol (2007) 25 (11):1315-21. doi: 10.1038/nbt1350

49. Boyd AL, Reid JC, Salci KR, Aslostovar L, Benoit YD, Shapovalova Z, et al. Acute Myeloid Leukaemia Disrupts Endogenous Myelo-Erythropoiesis by Compromising the Adipocyte Bone Marrow Niche. Nat Cell Biol (2017) 19 (11):1336-47. doi: 10.1038/ncb3625

50. Sheng X, Tucci J, Parmentier JH, Ji L, Behan JW, Heisterkamp N, et al. Adipocytes Cause Leukemia Cell Resistance to Daunorubicin via Oxidative Stress Response. Oncotarget (2016) 7(45):73147-59. doi: 10.18632/oncotarget.12246
51. Li Z, Hardij J, Bagchi DP, Scheller EL, MacDougald OA. Development, Regulation, Metabolism and Function of Bone Marrow Adipose Tissues. Bone (2018) 110:134-40. doi: 10.1016/j.bone.2018.01.008

52. Padro T, Ruiz S, Bieker R, Burger H, Steins M, Kienast J, et al. Increased Angiogenesis in the Bone Marrow of Patients With Acute Myeloid Leukemia. Blood (2000) 95(8):2637-44. doi: 10.1182/blood.V95.8.2637. 008k07_2637_2644

53. Fiedler W, Graeven U, Ergun S, Verago S, Kilic N, Stockschlader M, et al. Vascular Endothelial Growth Factor, a Possible Paracrine Growth Factor in Human Acute Myeloid Leukemia. Blood (1997) 89(6):1870-5. doi: 10.1182/ blood.V89.6.1870

54. Barbier V, Erbani J, Fiveash C, Davies JM, Tay J, Tallack MR, et al. Endothelial E-Selectin Inhibition Improves Acute Myeloid Leukaemia Therapy by Disrupting Vascular Niche-Mediated Chemoresistance. Nat Commun (2020) 11(1):2042. doi: 10.1038/s41467-020-15817-5

55. Tzankov A, Strasser U, Dirnhofer S, Menter T, Arber C, Jotterand M, et al. In Situ RHAMM Protein Expression in Acute Myeloid Leukemia Blasts Suggests Poor Overall Survival. Ann Hematol (2011) 90(8):901-9. doi: 10.1007/s00277-011-1159-6

56. Avigdor A, Goichberg P, Shivtiel S, Dar A, Peled A, Samira S, et al. CD44 and Hyaluronic Acid Cooperate With SDF-1 in the Trafficking of Human CD34 + Stem/Progenitor Cells to Bone Marrow. Blood (2004) 103(8):2981-9. doi: 10.1182/blood-2003-10-3611

57. Gruszka AM, Valli D, Restelli C, Alcalay M. Adhesion Deregulation in Acute Myeloid Leukaemia. Cells (2019) 8(1). doi: 10.3390/cells8010066

58. Le Dieu R, Taussig DC, Ramsay AG, Mitter R, Miraki-Moud F, Fatah R, et al. Peripheral Blood T Cells in Acute Myeloid Leukemia (AML) Patients at Diagnosis Have Abnormal Phenotype and Genotype and Form Defective Immune Synapses With AML Blasts. Blood (2009) 114(18):3909-16. doi: 10.1182/blood-2009-02-206946

59. Lim SH, Worman CP, Jewell AP, Goldstone AH. Cellular Cytotoxic Function and Potential in Acute Myelogenous Leukaemia. Leuk Res (1991) 15(7):641-4. doi: 10.1016/0145-2126(91)90033-p

60. Schmidt A, Oberle N, Krammer PH. Molecular Mechanisms of TregMediated T Cell Suppression. Front Immunol (2012) 3:51. doi: 10.3389/ fimmu.2012.00051

61. Zhang L, Gajewski TF, Kline J. PD-1/PD-L1 Interactions Inhibit Antitumor Immune Responses in a Murine Acute Myeloid Leukemia Model. Blood (2009) 114(8):1545-52. doi: 10.1182/blood-2009-03-206672

62. Robinson AJ, Davies S, Darley RL, Tonks A. Reactive Oxygen Species Rewires Metabolic Activity in Acute Myeloid Leukemia. Front Oncol (2021) 11:632623. doi: 10.3389/fonc.2021.632623

63. Mansour I, Zayed RA, Said F, Latif LA. Indoleamine 2,3-Dioxygenase and Regulatory T Cells in Acute Myeloid Leukemia. Hematology (2016) 21 (8):447-53. doi: 10.1080/10245332.2015.1106814

64. Ragaini S, Wagner S, Marconi G, Parisi S, Sartor C, Nanni J, et al. An IDO1Related Immune Gene Signature Predicts Overall Survival in Acute Myeloid Leukemia. Blood Adv (2022) 6(1):87-99. doi: 10.1182/bloodadvances. 2021004878

65. Rezaei M, Tan J, Zeng C, Li Y, Ganjalikhani-Hakemi M. TIM-3 in Leukemia; Immune Response and Beyond. Front Oncol (2021) 11:753677. doi: 10.3389/ fonc.2021.753677

66. Folgiero V, Cifaldi L, Li Pira G, Goffredo BM, Vinti L, Locatelli F. TIM-3/ Gal-9 Interaction Induces IFNgamma-Dependent IDO1 Expression in Acute Myeloid Leukemia Blast Cells. J Hematol Oncol (2015) 8:36. doi: 10.1186/s13045-015-0134-4

67. Xu L, Xu J, Ma S, Li X, Zhu M, Chen S, et al. High Tim-3 Expression on AML Blasts Could Enhance Chemotherapy Sensitivity. Oncotarget (2017) 8 (60):102088-96. doi: 10.18632/oncotarget.22141

68. Dama P, Tang M, Fulton N, Kline J, Liu H. Gal9/Tim-3 Expression Level is Higher in AML Patients Who Fail Chemotherapy. J Immunother Cancer (2019) 7(1):175. doi: 10.1186/s40425-019-0611-3

69. Chajuwan T, Kansuwan P, Kobbuaklee S, Chanswangphuwana C. Characteristics and Clinical Correlation of TIM-3 and PD-1/PD-L1 Expressions in Leukemic Cells and Tumor Microenvironment in Newly Diagnosed Acute Myeloid Leukemia. Leuk Lymphoma (2022) 63(2):450-6. doi: 10.1080/10428194.2021.1984454 
70. Han Y, Dong Y, Yang Q, Xu W, Jiang S, Yu Z, et al. Acute Myeloid Leukemia Cells Express ICOS Ligand to Promote the Expansion of Regulatory T Cells. Front Immunol (2018) 9:2227. doi: 10.3389/fimmu.2018.02227

71. Arandi N, Ramzi M, Safaei F, Monabati A. Overexpression of Indoleamine 2,3-Dioxygenase Correlates With Regulatory T Cell Phenotype in Acute Myeloid Leukemia Patients With Normal Karyotype. Blood Res (2018) 53 (4):294-8. doi: 10.5045/br.2018.53.4.294

72. Duell J, Dittrich M, Bedke T, Mueller T, Eisele F, Rosenwald A, et al. Frequency of Regulatory T Cells Determines the Outcome of the T-CellEngaging Antibody Blinatumomab in Patients With B-Precursor ALL. Leukemia (2017) 31(10):2181-90. doi: 10.1038/leu.2017.41

73. Menter T, Kuzmanic B, Bucher C, Medinger M, Halter J, Dirnhofer S, et al. Beneficial Role of Increased FOXP3(+) Regulatory T-Cells in Acute Myeloid Leukaemia Therapy Response. Br J Haematol (2018) 182(4):581-3. doi: 10.1111/bjh.14819

74. Szczepanski MJ, Szajnik M, Czystowska M, Mandapathil M, Strauss L, Welsh A, et al. Increased Frequency and Suppression by Regulatory T Cells in Patients With Acute Myelogenous Leukemia. Clin Cancer Res (2009) 15(10):3325-32. doi: 10.1158/1078-0432.CCR-08-3010

75. Di Ianni M, Falzetti F, Carotti A, Terenzi A, Castellino F, Bonifacio E, et al. Tregs Prevent GVHD and Promote Immune Reconstitution in HLA-Haploidentical Transplantation. Blood (2011) 117(14):3921-8. doi: 10.1182/blood-2010-10-311894

76. Tettamanti S, Pievani A, Biondi A, Dotti G, Serafini M. Catch Me If You Can: How AML and its Niche Escape Immunotherapy. Leukemia (2022) 36 (1):13-22. doi: 10.1038/s41375-021-01350-x

77. Jimbu L, Mesaros O, Popescu C, Neaga A, Berceanu I, Dima D, et al. Is There a Place for PD-1-PD-L Blockade in Acute Myeloid Leukemia? Pharm (Basel) (2021) 14(4). doi: 10.3390/ph14040288

78. Nabe S, Yamada T, Suzuki J, Toriyama K, Yasuoka T, Kuwahara M, et al. Reinforce the Antitumor Activity of CD8(+) T Cells via Glutamine Restriction. Cancer Sci (2018) 109(12):3737-50. doi: 10.1111/cas.13827

79. Mussai F, De Santo C, Abu-Dayyeh I, Booth S, Quek L, McEwen-Smith RM, et al. Acute Myeloid Leukemia Creates an Arginase-Dependent Immunosuppressive Microenvironment. Blood (2013) 122(5):749-58. doi: 10.1182/blood-2013-01-480129

80. Saito Y, Sawa D, Kinoshita M, Yamada A, Kamimura S, Suekane A, et al. EVI1 Triggers Metabolic Reprogramming Associated With Leukemogenesis and Increases Sensitivity to L-Asparaginase. Haematologica (2020) 105 (8):2118-29. doi: 10.3324/haematol.2019.225953

81. Mussai F, Wheat R, Sarrou E, Booth S, Stavrou V, Fultang L, et al. Targeting the Arginine Metabolic Brake Enhances Immunotherapy for Leukaemia. Int J Cancer (2019) 145(8):2201-8. doi: 10.1002/ijc.32028

82. Brune MM, Stussi G, Lundberg P, Vela V, Heim D, Manz MG, et al. Effects of Lenalidomide on the Bone Marrow Microenvironment in Acute Myeloid Leukemia: Translational Analysis of the HOVON103 AML/SAKK30/10 Swiss Trial Cohort. Ann Hematol (2021) 100(5):1169-79. doi: 10.1007/ s00277-021-04467-2

83. Gandhi AK, Kang J, Havens CG, Conklin T, Ning Y, Wu L, et al. Immunomodulatory Agents Lenalidomide and Pomalidomide CoStimulate T Cells by Inducing Degradation of T Cell Repressors Ikaros and Aiolos via Modulation of the E3 Ubiquitin Ligase Complex CRL4 (CRBN. ) Br J Haematol (2014) 164(6):811-21. doi: 10.1111/bjh.12708

84. Lopez-Girona A, Mendy D, Ito T, Miller K, Gandhi AK, Kang J, et al. Cereblon is a Direct Protein Target for Immunomodulatory and Antiproliferative Activities of Lenalidomide and Pomalidomide. Leukemia (2012) 26(11):2326-35. doi: 10.1038/leu.2012.119

85. Lindner S, Kronke J. The Molecular Mechanism of Thalidomide Analogs in Hematologic Malignancies. J Mol Med (Berl) (2016) 94(12):1327-34. doi: 10.1007/s00109-016-1450-z

86. Kao C, Oestreich KJ, Paley MA, Crawford A, Angelosanto JM, Ali MA, et al. Transcription Factor T-Bet Represses Expression of the Inhibitory Receptor PD-1 and Sustains Virus-Specific CD8+ T Cell Responses During Chronic Infection. Nat Immunol (2011) 12(7):663-71. doi: 10.1038/ni.2046

87. Jia B, Zhao C, Rakszawski KL, Claxton DF, Ehmann WC, Rybka WB, et al. Eomes (+)T-bet(Low) CD8(+) T Cells Are Functionally Impaired and Are Associated With Poor Clinical Outcome in Patients With Acute Myeloid Leukemia. Cancer Res (2019) 79(7):1635-45. doi: 10.1158/0008-5472.CAN-18-3107

88. Cheng Y, Wang X, Qi P, Liu C, Wang S, Wan Q, et al. Tumor Microenvironmental Competitive Endogenous RNA Network and
Immune Cells Act as Robust Prognostic Predictor of Acute Myeloid Leukemia. Front Oncol (2021) 11:584884. doi: 10.3389/fonc.2021.584884

89. Baragano Raneros A, Martin-Palanco V, Fernandez AF, Rodriguez RM, Fraga MF, Lopez-Larrea C, et al. Methylation of NKG2D Ligands Contributes to Immune System Evasion in Acute Myeloid Leukemia. Genes Immun (2015) 16(1):71-82. doi: 10.1038/gene.2014.58

90. Paczulla AM, Rothfelder K, Raffel S, Konantz M, Steinbacher J, Wang H, et al. Absence of NKG2D Ligands Defines Leukaemia Stem Cells and Mediates Their Immune Evasion. Nature (2019) 572(7768):254-9. doi: 10.1038/s41586-019-1410-1

91. Kong Y, Zhu L, Schell TD, Zhang J, Claxton DF, Ehmann WC, et al. T-Cell Immunoglobulin and ITIM Domain (TIGIT) Associates With CD8+ T-Cell Exhaustion and Poor Clinical Outcome in AML Patients. Clin Cancer Res (2016) 22(12):3057-66. doi: 10.1158/1078-0432.CCR-15-2626

92. Mantovani A, Sozzani S, Locati M, Allavena P, Sica A. Macrophage Polarization: Tumor-Associated Macrophages as a Paradigm for Polarized M2 Mononuclear Phagocytes. Trends Immunol (2002) 23(11):549-55. doi: $10.1016 / \mathrm{s} 1471-4906(02) 02302-5$

93. Al-Matary YS, Botezatu L, Opalka B, Hones JM, Lams RF, Thivakaran A, et al. Acute Myeloid Leukemia Cells Polarize Macrophages Towards a Leukemia Supporting State in a Growth Factor Independence 1 Dependent Manner. Haematologica (2016) 101(10):1216-27. doi: 10.3324/haematol.2016.143180

94. Yang Y, Li C, Liu T, Dai X, Bazhin AV. Myeloid-Derived Suppressor Cells in Tumors: From Mechanisms to Antigen Specificity and Microenvironmental Regulation. Front Immunol (2020) 11:1371. doi: 10.3389/fimmu.2020.01371

95. Kittang AO, Kordasti S, Sand KE, Costantini B, Kramer AM, Perezabellan P, et al. Expansion of Myeloid Derived Suppressor Cells Correlates With Number of T Regulatory Cells and Disease Progression in Myelodysplastic Syndrome. Oncoimmunology (2016) 5(2):e1062208. doi: 10.1080/2162402X.2015.1062208

96. Christopher MJ, Petti AA, Rettig MP, Miller CA, Chendamarai E, Duncavage EJ, et al. Immune Escape of Relapsed AML Cells After Allogeneic Transplantation. N Engl J Med (2018) 379(24):2330-41. doi: 10.1056/NEJMoa1808777

97. Epperly R, Gottschalk S, Velasquez MP. A Bump in the Road: How the Hostile AML Microenvironment Affects CAR T Cell Therapy. Front Oncol (2020) 10:262. doi: 10.3389/fonc.2020.00262

98. Perna F, Berman SH, Soni RK, Mansilla-Soto J, Eyquem J, Hamieh M, et al. Integrating Proteomics and Transcriptomics for Systematic Combinatorial Chimeric Antigen Receptor Therapy of AML. Cancer Cell (2017) 32(4):50619 e5. doi: 10.1016/j.ccell.2017.09.004

99. Jitschin R, Saul D, Braun M, Tohumeken S, Volkl S, Kischel R, et al. CD33/ CD3-Bispecific T-Cell Engaging (BiTE(R)) Antibody Construct Targets Monocytic AML Myeloid-Derived Suppressor Cells. J Immunother Cancer (2018) 6(1):116. doi: 10.1186/s40425-018-0432-9

100. Loskog A, Giandomenico V, Rossig C, Pule M, Dotti G, Brenner MK. Addition of the CD28 Signaling Domain to Chimeric T-Cell Receptors Enhances Chimeric T-Cell Resistance to T Regulatory Cells. Leukemia (2006) 20(10):1819-28. doi: 10.1038/sj.leu.2404366

101. Peled A, Tavor S. Role of CXCR4 in the Pathogenesis of Acute Myeloid Leukemia. Theranostics (2013) 3(1):34-9. doi: 10.7150/thno.5150

102. Brault L, Rovo A, Decker S, Dierks C, Tzankov A, Schwaller J. CXCR4SERINE339 Regulates Cellular Adhesion, Retention and Mobilization, and is a Marker for Poor Prognosis in Acute Myeloid Leukemia. Leukemia (2014) 28(3):566-76. doi: 10.1038/leu.2013.201

103. Riether C, Schurch CM, Ochsenbein AF. Regulation of Hematopoietic and Leukemic Stem Cells by the Immune System. Cell Death Differ (2015) 22 (2):187-98. doi: 10.1038/cdd.2014.89

104. Ladikou EE, Chevassut T, Pepper CJ, Pepper AG. Dissecting the Role of the CXCL12/CXCR4 Axis in Acute Myeloid Leukaemia. Br J Haematol (2020) 189(5):815-25. doi: 10.1111/bjh.16456

105. Shen ZH, Zeng DF, Kong PY, Ma YY, Zhang X. AMD3100 and G-CSF Disrupt the Cross-Talk Between Leukemia Cells and the Endosteal Niche and Enhance Their Sensitivity to Chemotherapeutic Drugs in Biomimetic Polystyrene Scaffolds. Blood Cells Mol Dis (2016) 59:16-24. doi: 10.1016/ j.bcmd.2016.03.009

106. Carey A, Edwards DKT, Eide CA, Newell L, Traer E, Medeiros BC, et al. Identification of Interleukin-1 by Functional Screening as a Key Mediator of Cellular Expansion and Disease Progression in Acute Myeloid Leukemia. Cell Rep (2017) 18(13):3204-18. doi: 10.1016/j.celrep.2017.03.018 
107. Nakase K, Kita K, Katayama N. IL-2/IL-3 Interplay Mediates Growth of CD25 Positive Acute Myeloid Leukemia Cells. Med Hypotheses (2018) 115:5-7. doi: 10.1016/j.mehy.2018.03.007

108. Vijay V, Miller R, Vue GS, Pezeshkian MB, Maywood M, Ast AM, et al. Interleukin-8 Blockade Prevents Activated Endothelial Cell Mediated Proliferation and Chemoresistance of Acute Myeloid Leukemia. Leuk Res (2019) 84:106180. doi: 10.1016/j.leukres.2019.106180

109. Diaz de la Guardia R, Lopez-Millan B, Lavoie JR, Bueno C, Castano J, Gomez-Casares M, et al. Detailed Characterization of Mesenchymal Stem/ Stromal Cells From a Large Cohort of AML Patients Demonstrates a Definitive Link to Treatment Outcomes. Stem Cell Rep (2017) 8(6):157386. doi: 10.1016/j.stemcr.2017.04.019

110. Sanjabi S, Zenewicz LA, Kamanaka M, Flavell RA. Anti-Inflammatory and Pro-Inflammatory Roles of TGF-Beta, IL-10, and IL-22 in Immunity and Autoimmunity. Curr Opin Pharmacol (2009) 9(4):447-53. doi: 10.1016/ j.coph.2009.04.008
Conflict of Interest: The authors declare that the research was conducted in the absence of any commercial or financial relationships that could be construed as a potential conflict of interest.

Publisher's Note: All claims expressed in this article are solely those of the authors and do not necessarily represent those of their affiliated organizations, or those of the publisher, the editors and the reviewers. Any product that may be evaluated in this article, or claim that may be made by its manufacturer, is not guaranteed or endorsed by the publisher.

Copyright $\odot 2022$ Menter and Tzankov. This is an open-access article distributed under the terms of the Creative Commons Attribution License (CC BY). The use, distribution or reproduction in other forums is permitted, provided the original author(s) and the copyright owner(s) are credited and that the original publication in this journal is cited, in accordance with accepted academic practice. No use, distribution or reproduction is permitted which does not comply with these terms. 